\title{
Análise em gênero, educação e tecnologias nas preferências e percepção de adolescentes em acesso à I nternet
}

\section{Analysing gender, education and technologies regarding adolescents preferences and perception while accessing the I nternet}

\section{Análisis en género, educación y tecnologías en las preferencias y percepción de adolescentes en acceso a Internet}

\section{Erika Giacometti-Rocha*}

Universidade Federal de São Carlos - UFSCar, São Carlos, São Paulo, Brasil

Daniel Mill**

Universidade Federal de São Carlos - UFSCar, São Carlos, São Paulo, Brasil

\begin{abstract}
RESUMO
Em análise de correlação do uso intensivo da Internet em computadores, notebooks, tablets, celulares, constatou-se não existir relação considerável entre usar intensamente a Internet e ser homem ou mulher. Entretanto, nas respostas sobre acesso de conteúdo, apareceu diferença significativa entre os gêneros. Em geral, chamou atenção 0 fato de mulheres adolescentes acessarem mais sobre beleza e menos sobre tecnologia em frequências de valores proporcionalmente inversos aos masculinos. Ao mesmo tempo acessam mais a Internet para estudar. Sob a leitura de Bourdieu, tentamos explicar essa diferença, embora não tenha sido possível apontar o caminho percorrido pelos adolescentes para chegar às preferências com base nos dados disponíveis. Contudo, questionados sobre quem lida melhor com tecnologias, a expressão das opiniões mostrou-se contraditória, diante das percepções do preconceito. Houve indicativo de autopercepção feminina negativa nessas respostas que pode explicar a fuga das mulheres da área de Ciência e Tecnologia. Em última instância, abre-se caminhos para educadores e pesquisadores pensar essa reprodução de estrutura social, baseada em gênero, manifesta nas escolhas dos sujeitos ao usar a Internet.
\end{abstract}

Palavras-chave: papéis de gênero, internet, Bourdieu, C\&T.

\section{ABSTRACT}

In analysis of the correlation of the intensive use of the Internet in computers, laptops, tablets, cell phones, it was verified that there was no relation between using the Internet intensely and being male or female. However, in the responses on content access, there was a significant difference between the genders. Overall, adolescent females access more 
beauty content and less technology in frequencies with values inversely proportional to that of males of the same age but more girls access the Internet to study. Under Bourdieu's reading, we tried to explain this difference, although it was not possible to point out the path taken by adolescents to arrive at preferences based on the available data. However, when we question about who is best at dealing with technologies, the expression of opinions has been contradictory to perceptions of prejudice. There was indicative of negative female self-perception in these responses that may explain the escape of women from the area of STEM area. Ultimately, there is a way for educators and researchers to think about this reproduction of gender-based social structure manifested in the subjects' choices when using the Internet.

Keywords: gender roles, internet, Bourdieu, STEM.

\section{RESUMEN}

En un análisis de correlación del uso intensivo de Internet en computadoras, ordenadores portátiles, tabletas, celulares, se constató que no existe relación considerable entre usar intensamente la Internet y ser hombre o mujer. Sin embargo, en las respuestas sobre acceso de contenido, apareció una diferencia significativa entre los géneros. En general, llamó la atención del hecho de que las mujeres adolescentes acceden más sobre belleza y menos sobre tecnología en frecuencias de valores proporcionalmente inversas a los masculinos. Al mismo tiempo acceden más a Internet para estudiar. Bajo la lectura de Bourdieu, intentamos explicar esta diferencia, aunque no fue posible apuntar el camino recorrido por los adolescentes para llegar a las preferencias con base en los datos disponibles. Sin embargo, cuestionados sobre quién maneja mejor con tecnologías, la expresión de las opiniones se mostró contradictoria ante las percepciones del prejuicio. Hubo indicativo de autopercepción femenina negativa en esas respuestas que puede explicar la fuga de las mujeres del área de Ciencia y Tecnología. En última instancia, se abren caminos para educadores e investigadores pensar esa reproducción de estructura social, basada en género, manifiesta en las elecciones de los sujetos al usar la Internet.

Palabras clave: papeles de género, internet, Bourdieu, Ciencia y Tecnología.

\section{I ntrodução}

A questão da identidade homem-mulher recebe força em nossa época e sociedade. Ainda se prega como norma as relações com papéis de gênero determinados, embora lutas marcadas pela pluralidade de subjetividades e suas vozes tenha se tornado mais evidente após o advento da Internet, que concentra mídias variadas e proporciona possibilidade de formação de grupos com muito mais facilidade.

Cabe ressaltar que, ao dizemos "papéis", existe uma restrição próxima à visão bourdiana do termo. Em uma interpretação, pode-se dizer que mulheres e homens desempenham funções não estanques. $\mathrm{Na}$ verdade, internalizam e assumem disposições de uma estrutura sistêmica manifestadas em práticas que soam, e muitas vezes são, regras de um jogo de poderes. 
Segundo o autor, é necessário compreender a relação de dominação entre os homens e as mulheres em todos os espaços sociais, ou seja, não somente na família, como também no universo escolar, no mundo do trabalho, no universo burocrático e no campo da mídia e, ainda, é preciso

deixar em pedaços a imagem fantasiosa de um eterno feminino, para fazer ver melhor a permanência da estrutura da relação de dominação entre os homens e as mulheres, que se mantém acima das diferenças substanciais da condição, ligadas aos momentos da história e às posições no espaço social. [...] os gêneros, longe de serem simples "papéis" com que se poderia jogar à vontade (à maneira das drag queens), estão inscritos nos corpos e em todo um universo do qual extraem sua força (Bourdieu, 2010, p. 61).

Ao esclarecer os papéis masculino e feminino arbitrariamente construídos ao longo da história, ressalta a construção simbólica deles relacionada a marcas biológicas (órgãos sexuais) e, por serem associados a elas, com o tempo, são vistos como "naturais". Nesse sentido, deve-se ultrapassar um simples senso de papéis desempenhados como naturais e entender os comportamentos condicionados do sujeito na sociedade.

Por essas razões, será usado o termo "gênero" (Bourdieu, 2010), apesar de haver ciência da complexidade e amplitude da discussão. 0 objetivo é observar as sutilezas dessa naturalização, principalmente no caso do papel feminino, em que o processo de condicionamento que lhe é atribuído repercute em perda de poderes na sociedade.

Segundo Bourdieu (p. 54), compreender "a distribuição estatística dos poderes e privilégios entre homens e mulheres, e sua evolução no decurso do tempo" é observar duas propriedades aparentemente contraditórias:

Por um lado, qualquer que seja a posição no espaço social, as mulheres têm em comum o fato de estarem separadas dos homens por um coeficiente simbólico negativo que, tal como a cor da pele para os negros, ou qualquer outro sinal de pertencer a um grupo social estigmatizado, afeta negativamente tudo que elas são e fazem, e está na própria base de um conjunto sistemático de diferenças (...) (Bourdieu, 2010, p. 56).

Bourdieu (2010), afirma também que as mulheres tendem a investir tempo, dinheiro e energia no trabalho de apresentação física, tratando-se a si mesmas como objetos estéticos. Assim, mulheres, principalmente as de elite, estudam mais. 
Sua crítica é de que, nesse caso, as mulheres não estão contribuindo para desconstrução do paradigma masculino. Na verdade, esse esforço apenas eleva seu valor até o ponto em que é permitido esse mesmo paradigma. Dessa forma, não cria valores novos, porque aceita os valores que são dados pelo próprio sistema.

Considerando ainda a cultura dos papéis de gênero exercidos pelos sujeitos,

O sistema de esquemas cognitivos que estão no princípio de construção da realidade e que são comuns, num determinado momento, ao conjunto de uma sociedade, constitui o inconsciente cultural, ou melhor, o "transcendental histórico" que serve de base ao senso comum (ou à doxa), isto é, a tudo aquilo que é "taken for granted", que é percebido como evidente (Bourdieu, 2013, p. 227).

O que é implícito, permeia e se reproduz nos meandros mais sutis, como o caso dos comportamentos manifestados também nas preferências e percepções dos adolescentes ${ }^{1}$ quando pesquisam assuntos de seus interesses na Internet.

Para Bourdieu, homens e mulheres diferem entre si dessa forma, enquanto seres que recebem da cultura características e valores e típicos e construídos arbitrariamente, de forma a serem vistos como "naturais" por grande parte da sociedade. Por essa razão, faz uma referência ao seu conceito de habitus para falar da percepção dos agentes tomada por esses esquemas de pensamento.

Assim, segundo ele, o mundo objetivo é interpretado seguindo a ordem lógica dessa divisão sexuada: os agentes irão agir e pensar conforme esses esquemas $e$ isso se refletirá no corpo, no comportamento e escolhas dos sujeitos (Bourdieu, 2010, p. 8).

No que tange às atuais investigações e teorias nas questões de gênero e tecnologia no Brasil, são enfatizadas as perspectivas do impacto das tecnologias sobre as representações sociais das mulheres nas questões relativas ao trabalho, ao direito, à saúde e à redistribuição de poder entre os sexos (Sarti, 2004, p. 41).

Em pesquisa de Mestrado, numa análise da correlação do uso intensivo da Internet em computadores, notebooks, tablets e celulares com diversas variáveis, havia o gênero. (Giacometti-Rocha, 2015). O coeficiente de correlação de Spearman para essa variável foi $-0,026$, quando um forte relacionamento positivo seria igual a 1 ou próximo de 1 . Não houve, portanto, indicativo de uma relação significativa entre usar intensamente a Internet e ser homem ou mulher. ${ }^{2}$

Contudo, nas respostas sobre acesso de conteúdo, apareceu diferença estatística relevante entre gênero e escolha de conteúdo, posteriormente classificados em categorias $(p$-valor $=0,000)$. Ao 
mesmo tempo, dados sobre empenho nos estudos revelaram que mulheres adolescentes estudam mais que homens de mesma idade na Internet, concordando com pesquisas que apontam o mesmo (Volman, 1997; Beltrão \& Alves, 2004; Araújo, 2001).

Desse modo, surgiu o questionamento: por que há pesquisas apontando mulheres nas universidades longe de áreas que são consideradas muito difíceis e cujo empenho parece necessário, como as da Ciência e Tecnologia se mulheres estudam mais? Isso despertou os questionamentos de como analisar esses dados.

Sob a leitura de Bourdieu (2010), busca-se explicar essa discrepância, embora não tenha sido possível apontar o caminho percorrido pelos adolescentes para chegar às suas preferências e percepções.

Em última instância, abre-se perspectiva de auxílio aos educadores e pesquisadores para pensar como essa reprodução de estrutura social baseada em gênero manifesta-se sutilmente nas escolhas e percepções dos sujeitos.

\section{Levantamento Bibliográfico}

Numa acepção ampla, a relação entre Gênero e Tecnologia pode ser entendida como um conjunto de construções socioculturais de ordem prática ou conceitual ligadas ao gênero na concepção, consumo ou uso de tecnologias. A Educação, nesse caso, entra como um pressuposto entre o gênero e a tecnologia.

Durante os anos 1990, no campo dos estudos de gênero, foram os escritos feministas, os quais, majoritariamente, abordaram a área da tecnologia inspirados na combinação de estudos culturais, antropologia e filosofia pós-moderna.

Gênero per se vem sendo discutida há algumas décadas. Connell e Pearse (2015) afirmam que o termo "gender" foi emprestado da gramática. Segundo as autoras, na gramática, "gênero" se tornou uma referência à distinção entre classes de substantivos "que correspondem mais ou menos a distinções de sexo".

Com base no Oxford Dictionary do século XIX, as autoras assinalam que o termo gênero vem de um radical que significa "produzir" ("generate", gerar) e que deu origem a palavras que significam "tipo", "classe" ou "espécie" ("genus", origem) em diversas línguas. No português, em semelhança, gênero é descrito como um conjunto de seres ou objetos que possuem a mesma origem ou que se acham ligados pela similitude de uma ou mais particularidades (Houaiss, 2009).

Connell e Pearse (2015) reforçam que, nesse contexto, as palavras podem ser generificadas (gendered), entendendo o termo como uma pessoa, grupo, espaço ou outra coisa passou ou foi tocado pela rede 
de processos das dinâmicas de gênero. Essas autoras afirmam a importância da língua, reconhecendo que isso não fornece um arcabouço consistente para compreendermos o gênero. Pode-se dizer que também não subsidia o entendimento do termo no campo da tecnologia.

Amplamente, gênero incorpora significados explicitamente relacionados às dimensões política, sexual e cultural. Esse processo deriva de forte influência dos estudos anglo-americanos a partir de Margaret Mead em 1935, indicando que, embora o sexo seja biológico, o comportamento sexual é uma construção social, instituindo a diferença entre "gênero" e "sexo" (Hirata, Laborie, Doaré, \& Senotier, 2009).

Esse instrumental serve aos estudos feministas para questionar os padrões patriarcais que definem o significado de ser "mulher" e ser "homem" (Louro, 1995). Na sequência, Butler (1990) propõe retirar a ideia de decorrência do sexo, analisando a arbitrariedade dessa distinção sexo/gênero. Trata-se de uma transformação no campo ao superar a discussão dos motivos dessa associação. Dessa forma, desconstrói essas noções não possíveis, justificando haver centenas de manifestações da sexualidade e comportamento variantes, inclusive entre culturas.

$\mathrm{Na}$ associação entre gênero e tecnologia, agendas feministas e estudos de gênero têm contribuído amplamente para o debate sobre a relação entre ciência e tecnologia ( $C \& T)$ e trabalho. Contudo, Cabral (2015) apresenta a dispersão nas publicações dos Estudos Feministas da Ciência e da Tecnologia no Brasil. A produção apresenta-se interdisciplinar: "educação em gênero, ciência e tecnologia", "carreiras" e "trajetórias de pesquisadoras" com lacunas quanto a abordagens das relações étnicas e raciais.

Ainda no campo C\&T, os estudos de gênero têm demonstrado o engano do senso comum em supor neutralidade nas produções e instituições. Segundo Silva (1998), o desafio básico de mudança da universalidade e racionalidade é introduzido pela perspectiva pósestruturalista e pós-moderna, particularmente dentro do feminismo e sobre o monopólio do conhecimento e das decisões pelos homens (brancos) das classes médias e altas. Tal crítica tem sido potente nos países europeus mais avançados e nos Estados Unidos, onde 0 feminismo é mais forte. Contudo, isso pode se aplicar ao Brasil.

Sob essa perspectiva, as mudanças científicas e tecnológicas envolvem interesses sociais, políticos e econômicos e tais interesses incorporam a cultura de gênero. Consequentemente, entende-se que os sistemas tecnológicos, implicitamente, colocam as experiências e investimentos do homem no centro da sua atenção sem reconhecer a sua especificidade. Ademais, mesmo se as tecnologias são concebidas com finalidades específicas em mente, o seu uso final não pode ser previsto ou controlado completamente: o utilizador ou consumidor de 
um artefato interage com ele e pode renegociar os seus significados e usos.

Como premissa, se as mulheres tiverem maior participação ativa nos processos de fabricação, comércio e consumo e inovação, o conhecimento e a tecnologia gerariam conhecimento e produtos tecnológicos sob um ponto de vista específico.

Historicamente, mulheres aderem menos que homens à área de Ciência e Tecnologia, especialmente dentro das chamadas "ciências duras": matemática, computação, engenharias, física etc. No mundo, mulheres nessa área totalizam uma média de 25 por cento (Allagnat et al., 2017) e, segundo a crítica feminista, a causa é a ciência e a tecnologia, tal como conhecemos, ser construída por homens e para homens, criando um viés. Como exemplo, Handley, Brown, MossRacusin e Smith (2015) indicam que estudantes de pós-graduação avaliam mais positivamente a ciência produzida por homens se comparada à produzida por mulheres; principalmente nas áreas tipicamente masculinas e mesmo entre aqueles que se consideram justos e objetivos. Argumentos contrários são reforçados, indicando que nas referências estatísticas mulheres são menos produtivas do que os homens. Nesse sentido, a crítica feminista aponta que muitos fatores influem, entre eles, as próprias construções sociais da produção científica predominantemente masculina.

Segundo Coimbra (2011), as respostas feministas a estas questões são complexas. O conhecimento feminista se tornou diverso e não há um só ponto de vista feminista em tópicos como o impacto da tecnologia em mulheres, ou o papel das mulheres numa sociedade de informação, o que dificulta determinar exatamente os problemas e suas resoluções nessa era.

Uma ideia comum é aumentar o número de rostos femininos na ciência, mas é necessário se tornarem conscientes dos mecanismos limitantes e do papel a ser realizado para não serem, as mulheres mesmas, perpetuadoras desses mecanismos. Para Fraser (1985), a teoria crítica tem apontado essas diferentes formas pelas quais a subordinação das mulheres tem se mantido.

Em termos de mercado, diversas autoras apontam que as conquistas femininas no campo educacional não foram acompanhadas, no mesmo sentido, por conquistas no mercado de trabalho. As mulheres reverteram o "hiato de gênero na educação", mas não reverteram a questão ocupacional e salarial, mesmo depois da globalização (Beltrão \& Alves, 2004; Araújo, 2001; Hirata, 2015).

Do ponto de vista da igualdade de gênero em relação às tecnologias, assenta no imaginário social que mulheres e homens são igualmente capazes de manusear tecnologias estando em contato com elas. Por essa razão, Bencivenga, Ramos, Maio e Festas (2008) afirmam que TDIC pode indiretamente ter profundos efeitos nos papéis de gênero, gênero e equidade e no empoderamento das mulheres. Contudo, há 
fortes indicativos da perpetuação do paradigma masculino associado às tecnologias.

Nos EUA, os jogos são frequentemente associados ao domínio de tecnologias, estratégias e raciocínio lógico e há introjeção de valores culturais de gênero sendo repassados, conforme Bian, Leslie e Cimpian (2017). A pesquisa indica que, nesse campo, meninas a partir dos 6 anos creem ser menos inteligentes que meninos e apresentam menos interesse nos jogos, quando estes são classificados para inteligentes, mas não quando esses mesmos jogos são classificados como atividade para persistentes. Evidencia-se, assim, a subjetividade permeada e marcada desde cedo pelo processo de generificação com relação às tecnologias e ao conhecimento associado a elas.

As possíveis diferenças no desempenho de sujeitos conforme 0 gênero ao longo da educação formal e podem servir como exemplo de como incide essa construção generificada. Volman, van Eck, Heemskerk e Kuiper (2005) investigou, na realidade holandesa, a acessibilidade e atratividade dos diferentes tipos de aplicações das TDIC na educação para meninas e meninos e para alunos de famílias de minoria étnica entre a população.

Anteriormente, Volman (1997) já aplicara uma pesquisa empírica para explicar porque mulheres são sub-representadas no âmbito das TDIC e como isso repercute no delineamento da formação da identidade feminina. Para ela, a diferença na utilização dos computadores por rapazes e moças não resulta de um problema inerente ao gênero. A autora cita um conjunto de estudos, no âmbito dos quais se verificou que, quando as mulheres adolescentes têm tempos de utilização dos computadores semelhantes aos homens, as diferenças entre gêneros diminuem visivelmente. A autora explica que essas diferenças entre os sexos são um fenômeno histórico e socialmente construído.

Nesse sentido, nos empregos técnicos ou tecnológicos, as relações sociais do gênero pautam-se no modo de organização do trabalho e da cultura masculina do posto de trabalho. Entende-se a relação com tecnologias como uma parte da identidade dos indivíduos. Além disso, afirma que as próprias meninas se excluem, definindo-se como outsiders, ao passo que os meninos se autointitulam experts. (Volman et al., 2005).

No Brasil, não foi encontrada, atualmente, pesquisa relevante sobre o papel dos gêneros no contexto das ciência e tecnologias na educação básica. Scielo e Google Acadêmico foram as bases de busca.

Quanto à ocorrência da naturalização, diversas pesquisas apareceram, ainda que não recorram ao trabalho de Bourdieu. São perspectivas que focalizam o gênero e a sexualidade sem que isso tenha qualquer relação com o advento das tecnologias. No entanto, apresentam formas de manutenção da naturalização do discurso 
heteronormativo. Um exemplo que nos interessou foi o trabalho de Vianna e Finco (2009). Observaram que a forma como a naturalização dos papéis binários de gênero é feita evidencia a composição das normas no sistema comparativo de informações disponíveis na sociedade ao classificar indivíduos e estabelecer sua relação com o coletivo.

Nesse contexto, a criança que não segue as regras é vista como transgressora, um "caso" ou um problema no âmbito da produtividade, do poder e do saber. Dessa forma, a manutenção desse modelo masculino-feminino apresentado diariamente às meninas e meninos ocorre por meio do ocultamento das masculinidades e feminilidades alternativas, do silêncio sobre elas e de sua marginalização.

\section{Método}

Este trabalho é fruto de uma investigação de natureza descritiva, que abordou a questão observada por meio de pesquisa quali-quantitativa e foi devidamente submetida aos procedimentos do Comitê de Ética, tendo sido autorizada.

O estudo buscou caracterizar algumas transformações postas aos sujeitos investigados pelas tecnologias digitais, levando em conta outros componentes da situação em suas interações e influências.

Como instrumentos para levantamento de dados, questionários e entrevistas foram adotados. O questionário, embora estruturado e objetivo, apresentou algumas questões com opção para o sujeito investigado comentar/registrar suas opiniões sobre certos assuntos.

Desses comentários, extraíram-se dados analisados neste artigo. Para garantir maior amostragem, os questionários foram aplicados em material impresso. Posteriormente, os dados foram sistematizados em banco de dados digital. Para sistematização e análise, adotou-se as ferramentas do Access ${ }^{\circledR}$ e Excel ${ }^{\circledR}$ e o software SPSS 24.

O questionário com algumas questões abertas a comentários foi aplicado a 760 adolescentes, sendo aproveitadas as respostas de 533 participantes. A aplicação ocorreu em três escolas da rede privada e em três, da pública.

Após organizar e sistematizar os dados, elaborou-se e analisou-se quadros, tabelas e figuras. O processo de sistematização dos dados em categorias de análise envolveu a observação de regularidades e padrões (Bogdan \& Biklen, 1999, p. 125). 


\section{Resultados e Discussão}

Conforme dados recolhidos, há $260(48,78 \%)$ dos participantes do gênero feminino e $273(51,22 \%)$ dos participantes do gênero masculino.

Os dados aproximam-se aos dos fornecidos pelo relatório nacional brasileiro (Barbosa, 2014), no qual a distribuição de participantes por sexo foi de $48 \%$ para o masculino e $52 \%$ para o feminino.

No questionário a abordagem não adotou os diversos gêneros hoje oficializados, mas presume-se a declaração do feminino e masculino como adotada livremente, independente do sexo, a gosto do participante, ainda que a situação não seja a ideal. A grande maioria dos entrevistados (69\%) estuda ou estudou em escola pública; $20,8 \%$ estudam em escola privada $6,9 \%$ mudou da pública para privada e $3,2 \%$ mudou da privada para a pública.

Ao total, $385(72,2 \%)$ dos participantes estudantes são de escolas públicas. Esse desequilíbrio na amostra ocorreu porque, nas escolas públicas, o número de estudantes foi muito maior do que nas escolas particulares da pesquisa.

Conforme a tabela 1 , as categorias de conteúdo extraídas dos comentários dos participantes são: beleza, tecnologias e jogos, relacionamento, atualidades, compras, entretenimento geral, educação escolar e trabalho, religião e, finalmente, saúde.

Tabela 1.

Conteúdos acessados na Internet pelos participantes.

\section{Quantidade de respostas}

Categorias

(número de participantes e percentual)

\begin{tabular}{ccc}
\cline { 2 - 3 } & Feminino & Masculino \\
\hline Beleza & $21(4,97 \%)$ & $1(0,23 \%)$ \\
\hline Tecnologias & $4(0,94 \%)$ & $24(5,7 \%)$ \\
\hline Relacionamento & $21(4,97 \%)$ & $37(8,77 \%)$ \\
\hline Atualidades & $16(1,42 \%)$ & $17(4,02 \%)$ \\
\hline Compras & $3(0,71 \%)$ & $90(1,66 \%)$ \\
\hline $\begin{array}{c}\text { Entretenimento } \\
\text { geral }\end{array}$ & $101(23,93 \%)$ & $26(6,16 \%)$ \\
\hline Escola e trabalho & $46(10,9 \%)$ & $2(0,47 \%)$ \\
\hline Religião & $2(0,47 \%)$ & $2(0,47 \%)$
\end{tabular}

Nota. Existe uma diferença estatística entre gênero e escolha de categorias ( $p$-valor $=0,000)$. 
Retomando o argumento de Bourdieu (2010), esses dados podem reforçar que mulheres tendem a investir tempo, dinheiro e energia no trabalho de apresentação física, tratando-se a si mesmas como objetos estéticos. Entre nossas participantes, isso se mostra acesso mais frequente à beleza $(4,97 \%)$. Entre rapazes, houve respostas para este critério, totalizando $0,23 \%$. Em contrapartida, as participantes acessam conteúdos de tecnologias em $0,94 \%$ ao passo que os participantes, $5,7 \%$. São medidas aproximadamente inversas para as categorias conforme o gênero. Além disso, destaca-se as porcentagens maiores de acessos femininos em escola e trabalho ( $10,9 \%$ contra $6,16 \%$ dos meninos).

Para aprofundar a questão, apresenta-se dados sobre o uso da Internet com a finalidade de estudar na tabela 2.

Ressalta-se que o questionário levou os participantes a direcionar respostas aos estudos e formação de grupos de estudo na Internet para e na escola.

Desse modo, embora haja um viés da educação informal, há um peso muito maior de conteúdos pensados com base na educação formal.

Tabela 2.

Distribuição de participantes por gênero que usam a Internet para estudar.

Usa a internet para estudar?

\begin{tabular}{c|c|c}
\hline & Mulher & Homem \\
\hline Sim & $226(86,92 \%)$ & $218(79,85 \%)$ \\
\hline Não & $34(13,08 \%)$ & $55(20,15 \%)$ \\
\hline Total & \multicolumn{2}{|c|}{$533(100 \%)$} \\
\hline
\end{tabular}

De acordo com o resultado, entende-se uma confirmação dos comentários classificados em categorias na Tabela 1. Lá, mulheres acessam com mais frequência conteúdos de estudo e trabalho (10,9\% contra $6,16 \%$ de respostas masculinas). Já na tabela 2 , houve aproximadamente $7 \%$ mais respostas de meninas usando a Internet para estudos $(86,92 \%$ das moças contra $79,85 \%$ dos rapazes). Isso indica maior interesse educacional na Internet por parte das estudantes do gênero feminino.

Sobre o uso do computador para estudar, haveriam mais questões a serem consideradas, se comparamos com o trabalho de Volman (1997) e Volman et al. (2005).

Em Volman (1997), afirma-se que os alunos entram na sala de aula com padrões de comportamento e atitudes vinculados ao gênero, mas sugerem que a educação desempenha um papel importante. Após um curso, as diferenças de conhecimento sobre informática entre meninas e meninos diminuíram. No entanto, o curso não foi 
capaz de remover as diferenças de gênero em atitudes. Além disso, para estudantes que trabalharam com um método não-gênero, as diferenças de gênero nas atitudes aumentaram. A autora concluiu que os eventos e experiências na sala de aula contribuem para a extensão dos repertórios de alunos específicos de gênero.

Outro ponto interessante é apresentado em Volman et al. (2005, p. 45-46). Os autores mostraram haver poucas diferenças de gênero nas habilidades em TIC na escola primária, especialmente no interesse dos computadores e na autoconfiança no uso do computador. No entanto as diferenças de gênero são maiores no ensino secundário do que no ensino primário, pois as respostas das meninas da escola secundária às questões sobre a atitude das TIC foram menos positivas, tanto quanto de garotos de minorias étnicas analisados (Volman et al., 2005, p. 46) ${ }^{3}$.

Esses pesquisadores encontraram outras diferenças de gênero no comportamento relacionado ao computador: na escola secundária, meninos querem saber mais sobre computador. Eles dizem mais frequentemente que gostam de estudar pelo computador, que gostam de aulas pelo computador, assim como também afirmam mais ter controle do computador do que meninas. (Volman et al., 2005, p. 46-47).

Aponta-se que os dados desta pesquisa podem ter uma intersecção com a questão da condição socioeconômica e cultural. Os participantes são de maioria das escolas públicas (em torno de $70 \%$ ).

Para fechar os resultados, apresenta-se a opinião dos adolescentes sobre quem lida melhor com as tecnologias. Esse dado serve para confrontar a percepção que estes mesmos adolescentes têm sobre o tema do preconceito. Os dois conjuntos de dados combinados podem ser associados à relação entre empenho nos estudos e percepção de serem capazes de seguir no futuro carreiras das áreas de Ciência e Tecnologia.

Seguem as tabelas 3 e 4 .

Tabela 3.

Opinião sobre gênero que lida melhor com tecnologias.

Na sua opinião, quem lida melhor com as tecnologias digitais?

\begin{tabular}{l|l|l}
\hline & Mulher & Homem \\
\hline Homem & $20(7,69 \%)$ & $89(32,60 \%)$ \\
\hline Ambos & $195(75,0 \%)$ & $172(63,0 \%)$ \\
\hline Mulher & $44(16,92 \%)$ & $11(4,03 \%)$ \\
\hline Omissos (sistema) & 2 & \\
\hline Total & $533(100 \%)$ & \\
\hline
\end{tabular}


Atentar para o fato de na tabela 3 as opiniões serem mais frequentes para a resposta ambos $(75 \%$ de respostas femininas e $63 \%$, masculinas). Contudo, $16 \%$ das mulheres responderam serem elas quem melhor lida com tecnologias e o dobro dessa porcentagem de respostas $(32,6 \%)$ de homens para afirmar serem eles quem o faz.

Tabela 4.

Percepção de preconceito de gênero na competência sobre tecnologias.

Há preconceito sobre a diferença de competências Fem. ou Masc.?

\begin{tabular}{l|l|l}
\hline & Mulher & Homem \\
\hline Sim & $126(48,46 \%)$ & $106(38,83 \%)$ \\
\hline Não & $48(18,46 \%)$ & $77(28,21 \%)$ \\
\hline Não sabe & $86(33,08 \%)$ & $88(32,23 \%)$ \\
\hline Omissos (sistema) & 2 & \\
\hline Total & $533(100 \%)$ & \\
\hline
\end{tabular}

Simultaneamente, um maior número de mulheres e homens apresentaram a opinião de serem igualmente capazes de lidar com as tecnologias estando em contato com elas. Ao mesmo tempo, as maiores porcentagens de respostas sobre a percepção do preconceito para ambos os gêneros $(48,46 \%$ mulheres e $38,83 \%$ homens) indicam que ambos percebem, embora as mulheres estejam em maior número.

\section{Conclusão}

Os conceitos de Bourdieu nos servem de instrumentos para interpretar que, em todo o sistema práticas sociais arbitrariamente construídas são internalizadas, naturalizadas e quase invisíveis na percepção dos próprios sujeitos. Ressalta-se que essas estruturas favorecem uns e desfavorecem outros de forma implícita. Entretanto, para propor mudanças, a questão da naturalização precisa ser explicada em termos de como isso acontece.

Evidenciamos pesquisas apontando muitas mulheres nas universidades longe de áreas consideradas difíceis e cujo empenho parece necessário, como é o caso da Ciência e Tecnologia no Brasil. Apesar disso, parece curioso como mais mulheres do que homens desde cedo esforçam-se para progredir nos estudos. Em levantamento bibliográfico, os argumentos caminham para a ideia de que, enquanto a ciência e as tecnologias desenvolvidas forem um campo predominantemente masculino, continuaremos com uma 
ciência, seus produtos e consumo generificados pelo viés masculino, tal como ainda é hoje.

Neste trabalho, observou-se conteúdo de pesquisa na Internet de ambos os gêneros e constatou-se que meninas acessam mais itens do critério beleza e menos tecnologia e jogos em valores proporcionalmente inversos aos acessos dos meninos, evidenciando as distintas práticas sociais femininas das masculinas, por critérios típicos.

Ao mesmo tempo, meninas apresentam porcentagens maiores para acesso a conteúdo sobre educação e trabalho, aparentemente reforçando o argumento de Bourdieu de elas estudariam mais, elevando-se até certo ponto.

Sua crítica é de que mulheres que buscam educação costumam não contribuir para desconstrução do paradigma masculino, por não criar valores novos e aceitando os valores ofertados pelo próprio sistema.

Assim, interpreta-se que caso estude e se preocupe um pouco mais em se envolver com as tecnologias, isso vai até o limite em que atinja o objetivo de garantir certa independência com um emprego na atual conjuntura socioeconômica, mas a evidente preocupação com a beleza a níveis muito mais elevados do que os masculinos pode ser um sinal de que a mulher ainda se pauta nos valores de dominância masculina.

Mesmo se os homens sofrem esse processo, isso tende a ser velado. As porcentagens de acesso do grupo masculino ao critério beleza é por si um princípio indicativo de algo secundário ou, ao menos, latente, pelo fato de que os cuidados com beleza serem característica historicamente associada ao feminino.

Pode-se discordar do autor, afirmando que ambos os sexos são preocupados em atrair um par através de cuidados com o corpo. Mas o número menor de respostas do grupo masculino sinaliza a concordância a explicação bourdiana, a partir do momento em que o sujeito "encobre" um fato quando há oportunidade de expressão social.

Em outras palavras, a preocupação poderia ser também masculina, mas admiti-lo seria ressaltar essa característica associada ao feminino e isso não é culturalmente aceito no universo de dominância masculina. Essa é uma hipótese que precisaria ser verificada em pesquisa. A priori, aceita-se a possibilidade desse viés nas respostas. Nesse ponto, seria interessante relembrar a hipótese de Vianna e Finco (2009) que entende a adoção da heteronormatividade como uma forma de não ser visto como um transgressor.

Com toda essa constatação, procuramos mais pistas por meio do questionamento da opinião e percepção sobre o lidar com as tecnologias para tornar claro que uma mudança cultural deve ir muito além do simples acesso a tecnologias e estudo. 
Não pudemos apresentar dados sobre o como a naturalização ocorre, mas pôde-se denunciar sua presença. Ao mesmo tempo um maior número de mulheres e homens teriam opinião de serem igualmente capazes de lidar com as tecnologias, estando em contato com elas há indicação da manutenção do status quo masculino.

As porcentagens de respostas vindas de rapazes e moças apontam a percepção de preconceito de gênero sobre lidar com tecnologias, ainda que reconheçam em maioria que ambos são capazes. Corrobora a tendência apontada por Volman (2005) de que meninas tendem a se considerar outsiders e os rapazes experts nesse campo, ainda que a maioria das respostas tenham mostrado a opinião de que ambos os gêneros são capazes de lidar com a tecnologia. A expressão da opinião mostrou-se uma espécie de "discurso politicamente correto", diante das percepções do preconceito.

Nesse contexto, há um indicativo de que a precoce autopercepção feminina negativa construída socialmente sobre suas habilidades apontadas em Bian, Leslie e Cimpian (2017) pode ser identificada até a idade adolescente. Do mesmo modo, Volman (1997) indicou que essa percepção negativa ocorre no secundário (ensino médio) e muito menos no primário, sugerindo o "como" o contexto escolar pode contribuir para essa percepção.

Também é muito interessante pensar que os dados desta pesquisa podem ter uma intersecção com a questão da condição socioeconômica e cultural. Os participantes são de maioria das escolas públicas (em torno de $70 \%$ ). Volman et al. (2005), por exemplo, evidenciaram que garotas do "ensino secundário" não têm expectativas tanto quanto garotos estudantes de contextos de minorias étnicas. Infelizmente, não houve pergunta sobre etnia, então há uma restrição para esse cruzamento que seria do interesse de muitos pesquisadores hoje no Brasil. Assim, essa questão precisa ser aprofundada.

Uma das perguntas que surgem é quais são as escolhas e oportunidades prospectadas pelas adolescentes? E qual seria a relação com a questão da escala racial brasileira? A perspectiva de mercado ofertada aos jovens é um importante fator de impulso, lembrando que diversas autoras apontam que as conquistas femininas no campo educacional não foram acompanhadas, no mesmo sentido, por conquistas no mercado de trabalho. As mulheres conquistaram espeço na educação, mas não reverteram a questão ocupacional e salarial, mesmo depois da globalização. 


\section{Referências}

Allagnat, L., Berghmans, S., Falk-Krzesinski, H. J., Hanafi, S., Herbert, R., Huggett, S., \& Tobin, S. (2017). Gender in the Global Research Landscape. Elsevier, $96 . \quad$ doi: https://doi.org/10.17632/bb3cjfgm2w.2

Andrade, M., Franco, C., \& de Carvalho, J. P. (2003). Gênero e desempenho em matemática ao final do ensino médio: quais as relações? Estudos em Avaliação Educacional, (27), 77-96.

Araújo, A. M. C. (2001). Gênero no trabalho. Cadernos Pagu, (17/18), 131-138.

Barbosa, A. F. (2014). Pesquisa sobre o uso das tecnologias de informação e comunicação nas escolas brasileiras: TIC Educação 2013. São Paulo: Comitê Gestor da Internet no Brasil. Retirado de http://www.cetic. br/media/docs/publicacoes/2/tic-educacao2013.pdf

Barreto, M. D. P. S. L. (2004). Patriarcalismo e o Feminismo: uma retrospectiva histórica. Revista Ártemis, (1), 64-73.

Beltrão, K. I., \& Alves, J. E. D. (2004). A reversão do hiato de gênero na educação brasileira no século XX. Anais do XIV Encontro Nacional de Estudos Populacionais, ABEP, 1-24.

Bencivenga, R., Ramos, J. L., Maio, V., \& Festas, M. (2008). "Ciao Women": Contributos para o estudo das necessidades de aprendizagem ao longo da vida específicas de mulheres adultas em relação às TIC. Educação, Formação \& Tecnologias, 1(1), 1122.

Bian, L., Leslie, S., \& Cimpian, A. (2017). Gender stereotypes about intellectual ability emerge early and influence children's interests. Science, 391(6323), 389-391.

Bogdan, R., \& Biklen, S. (1999). Investigação qualitativa em Educação: Uma introdução à teoria dos métodos. Porto: Porto Editora.

Bourdieu, P. (2010). A dominação masculina. Rio de Janeiro: Bertrand Brasil.

Bourdieu, P. (2013). O inconsciente da escola. Pro-Posições, 24(3), 227-233.

Brasil. (2014). Pesquisa brasileira de mídia 2014: hábitos de consumo de mídia pela população brasileira. Brasília: Secom (Presidência da República. Secretaria de Comunicação Social).

Butler, J. (1990). Gender Trouble: Feminism and the Subversion of Identity. New York: Routledge.

Cabral, C. (2015). Os Estudos Feministas da Ciência e da Tecnologia no Brasil: Reflexões sobre Estilos e Coletivos de Pensamento. Revista Ártemis, 20(2), 76-91. https://doi.org/10.15668/18078214/artemis.v20n2p76-91 
Carvalho, M. P. D. (2003). Sucesso e fracasso escolar: uma questão de gênero. Educação e Pesquisa, 29(1), 185-193.

Coimbra, U. D. E. (2011). Mulheres, tecnologias e comunicação: para além das receitas. Media \& J ornalismo, 10(18), 62-83.

Connell, R. \& Pearse, R. (2015). Gênero: uma perspectiva global. São Paulo: Versos.

Fischer, R. M. B. (2001). Mídia e educação da mulher: uma discussão teórica sobre modos de enunciar o feminino na TV. Estudos Feministas, 9(2), 586-599.

Fraser, N. (1985). What's critical about critical theory? The case of Habermas and gender. New German Critique, (35), 97-131.

Giacometti-Rocha, E. (2015). Análise das Tecnologias Digitais de Informação e Comunicação como mediadoras de relações e da construção do conhecimento de adolescentes (Dissertação de Mestrado). Universidade Federal de São Carlos, São Carlos.

Handley, I. M., Brown, E. R., Moss-Racusin, C. A., \& Smith, J. L. (2015). Quality of evidence revealing subtle gender biases in science is in the eye of the beholder. Proceedings of the National Academy of Sciences, 112(43), 13201-13206.

Hirata, H. H. H. (2015). Globalização, trabalho e gênero. Revista de Políticas Públicas, 9(1), 111-128.

Hirata, H., Laborie, F., Doaré, H., \& Senotier, D. (2009). Dicionário Crítico do feminismo. São Paulo: UNESP.

Houaiss, A. (2009). Dicionário eletrônico Houaiss-versão 1.0. Instituto Antônio Houaiss. Rio de Janeiro: Objetiva.

Louro, G. L. (1995). Gênero História e Educação. Educação E Realidade, 20(2), 101-132.

Mead, M. (2000). Sexo e Temperamento. São Paulo: Perspectiva.

Mill, D., \& Fidalgo, F. (2010). O trabalho da mulher na educação a distância da idade mídia: sobre teletrabalho, tecnologia e relações de sexo. Faces de Eva, (24), 25-52.

Sarti, C. A. (2004). O feminismo brasileiro desde os anos 1970: revisitando uma trajetória. Estudos feministas, 12(2), 35-50.

Silva, E. B. (1998). Des-Construindo Gênero Em Ciência E Tecnologia. Cadernos Pagu, (10), 7-20.

Tanner, J. M. (1962). Growth at adolescence. Oxford: Blackwell.

Vianna, C., \& Finco, D. (2009). Meninas e meninos na Educação Infantil: uma questão de gênero e poder. Cadernos Pagu, (33), 265- 283.

Volman, M. (1997). Gender-related effects of computer and information literacy education. Journal of Curriculum Studies, 29(3), 315-328.

Volman, M., van Eck, E., Heemskerk, I., \& Kuiper, E. (2005). New technologies, new differences. Gender and ethnic differences in pupils' use of ICT in primary and secondary education. Computers \& Education, 45(1), 35-55. 


\section{Endereço para correspondência \\ Erika Giacometti-Rocha}

Universidade Federal de São Carlos - UFSCar

Departamento de Educação

Rodovia Washington Luís, s/n, Km 235, CEP 13565-905, São Carlos - SP, Brasil

Endereço eletrônico: erikagiacometti@gmail.com

\section{Daniel Mill}

Universidade Federal de São Carlos - UFSCar

Departamento de Educação

Rodovia Washington Luís, s/n, Km 235, CEP 13565-905, São Carlos - SP, Brasil

Endereço eletrônico: mill.ufscar@gmail.com

Recebido em: 18/06/2016

Reformulado em: 28/02/2018

Aceito em: 22/03/2018

\section{Notas}

* Doutoranda em Educação pela UFSCar (2016). Mestrado em Ciência Tecnologia e Sociedade (PPGCTS) pela UFSCar. Pesquisou o impacto sociocultural e cognitivo das TDIC com fomento da Coordenação de Aperfeiçoamento de Pessoal de Nível Superior (Capes). Graduação em Letras-Francês pela Universidade Estadual Paulista Júlio de Mesquita Filho - UNESP. Integrante do Grupo Horizonte (Grupo de Estudos e Pesquisas sobre Inovação em Educação, Tecnologias e Linguagens) e do Grupo de Teoria Crítica e Educação da UFSCar. Tutora Virtual na SEaD - UFSCar e Professora na Especialização Edutec-SEaD/UFSCar, fomentado pelo Programa de Incentivo ao Desenvolvimento Institucional, Científico e Tecnológico (PIDICT). Atualmente, pesquisa a influência dos estereótipos de gênero entre os adolescentes para a escolha por carreiras de C\&T pela teoria crítica.

** Professor da Universidade Federal de São Carlos (UFSCar). Docente e Gestor de Educação a Distância (EaD). Doutor em Educação pela UFMG, com pós-doutorado sobre "Gestão estratégica da EaD" (UAb-Portugal) e em "Produção científica em EaD" (Universidade de Coimbra). Membro dos Programas de Pós-Graduação em Educação e em Ciência, Tecnologia e Sociedade. Líder do Grupo Horizonte (Grupo de Estudos e Pesquisas sobre Inovação em Educação, Tecnologias e Linguagens). Pesquisador com interesse particular pela interseção das temáticas: Trabalho Docente, Tecnologias, Linguagens, Cognição e Educação a Distância.

${ }^{1}$ Conforme Tanner (1962), a adolescência compreende o período de transição entre a infância e a vida adulta, caracterizado pelos impulsos do desenvolvimento físico, mental, emocional, sexual e social e pelos esforços do indivíduo em alcançar os objetivos relacionados às expectativas culturais da sociedade em que vive. A faixa etária (ou limites cronológicos) para a adolescência é definida pela Organização Mundial da Saúde (OMS), como sendo dos 10 aos 19 anos (adolescents), critério este usado principalmente para fins estatísticos e políticos. (...). No Brasil, o Estatuto da Criança e do Adolescente (ECA, Lei 8.069/1990), considera criança a pessoa até 12 anos de idade incompletos e define a adolescência como a faixa etária de 12 a 18 anos de idade (Art. 2); e, em casos excepcionais e quando disposto na lei, o estatuto é aplicável até os 21 anos de idade (Art. 121 e 142).

2 Para a variante gênero, p-valor (Pearson) $=0,529$. Para uso intensivo, considerou-se todos os resultados em que os participantes responderam usar a Internet por mais de 3 horas diárias, tendo como base uma média nacional extraída da pesquisa brasileira de mídia (Brasil, 2014).

${ }^{3} \mathrm{Na}$ Holanda, ensino secundário corresponde ao nosso Ensino Médio. 
Erika Giacometti-Rocha, Daniel Mill

Este artigo de revista Estudos e Pesquisas em Psicologia é licenciado sob uma Licença Creative Commons Atribuição-Não Comercial 3.0 Não Adaptada. 